\title{
Case Study of Atmospheric Retrievals of MWHTS aboard FY-3C Satellite
}

\author{
Jieying He, Shengwei Zhang, Na Li \\ Key Laboratory of Remote Sensing, National Space Science Center, Chinese Academy of Sciences, Beijing, China \\ Email: hejieying@mirslab.cn
}

How to cite this paper: He, J.Y., Zhang, S.W. and Li, N. (2019) Case Study of Atmospheric Retrievals of MWHTS aboard FY-3C Satellite. Atmospheric and Climate Sciences, 9, 264-273. https://doi.org/10.4236/acs.2019.92018

Received: December 12, 2018

Accepted: April 21, 2019

Published: April 24, 2019

Copyright $\odot 2019$ by author(s) and Scientific Research Publishing Inc. This work is licensed under the Creative Commons Attribution International License (CC BY 4.0).

http://creativecommons.org/licenses/by/4.0/

(c) (i) Open Access

\begin{abstract}
The mesoscale numerical model WRF is used to simulate the No. 8 hurricane Matthew in 2016. The radar and radiometer observations are assimilated by WRF Var. With the verification to the real situation, the process of the hurricane rainstorm is well simulated by WRF in this case that it could basically show the hurricane evolution. We use the simulation results which are model outputs with high spatial and temporal resolution to do diagnostic analysis on the short term heavy rainstorm caused by Matthew, with a comparison between the best track and forecasting tracks using active and passive microwave observations from WRFDA model. In order to analyze the inner structure, the nadiral satellite-based observations were matched between the Microwave Humidity and Temperature Sounder (MWHTS) instrument aboard the FY-3C polar-orbiting platform since Sept 30, 2013 and dual-frequency radar named PR aboard GPM satellite and then separate retrievals are demonstrated in data assimilation for extreme weather with the retrieved root-mean-square errors of about $0.9 \mathrm{~K}$ and $17 \%$ and $10 \mathrm{~mm} / \mathrm{h}$ for precipitation products, which demonstrates the impact of $118 \mathrm{GHz}$ observations in data assimilation model.
\end{abstract}

\section{Keywords}

WRF, MWHTS, Matthew Hurricane, Track, 118-GHz

\section{Introduction}

Accurate profile and hydrometer retrievals around the globe are crucial for applications, such as in extreme weather event cases. By estimating the direct interaction of the radiation with atmospheric parameters in atmospheric column, data from microwave radiometers, thus, can be used to provide physically reasonable retrievals. A physical-based retrieval algorithm was introduced by Petty [1] aiming at inverting multichannel microwave radiances to determine physical 
information on temperature and hydrometeors. The Goddard Profiling Algorithm is a noteworthy system which uses a Bayesian inversion for all surface types, and now has been evolved to a fully parametric approach used operationally on global precipitation measurement (GPM) microwave imager (GMI) [2]. The microwave-integrated retrieval system (MiRS,

https://www.star.nesdis.noaa.gov/mirs/), which has been operational since 2007 at the National Oceanic and Atmospheric Administration (NOAA), is an inversion algorithm based on physical forward modeling and can invert observed multichannel radiances simultaneously to determine key components of the atmosphere and surface state.

At present, traditional mathematic modeling methods, such as multi-analysis, and time series analysis, are widely used in the statistical prediction method to forecast typhoon track [3] [4], in which the future state of prediction object is forecasted through a statistical prediction equation. Ensemble numerical prediction (ENP) is a novel technique developed in the past ten and odd year, and the ENP model, whether created by using model configurations with different model physical process parameterization schemes or by different model initial conditions from a Monte Carlo approach, formally consists of many different ensemble members.

This paper is organized as follows. The microwave instrument is first introduced, and it is demonstrated that multiple receiver arrays can be used to multiplex a large set of channels onto a single spot on the ground. An overview of the data sets and physical models used in the simulation is provided. We next point out that $118 \mathrm{GHz}$ as the unique adoption on polar-orbiting business satellite provide abundant layered information about temperature and humidity distribution. Then this paper adapts two methods to realize data assimilation based on profiles and radiance separately and in combination, and then compare with the impacts in 1Dvar model [5]. Finally, we summarize and provide suggestions for further research and development of data application about polar-orbital satellite.

\section{Description of Instrument}

Currently, there are several satellites in operation that are equipped with high-frequency microwave sensors, including the Advanced Microwave Sounding Unit B or Microwave Humidity Sounder on the National Oceanic and Atmospheric Administration and Metop series satellites, ATMS (advanced technology microwave sounder) on the NPP satellite and MicroWave Humidity and temperature Sounder (MWHTS) on the Chinese FY-3C satellite.

The Microwave humidity and temperature Sounder (MWHTS) is flown onboard FY-3C satellites. The instruments have been working since September 30, 2013. The MWHTS has 15 channels and is mainly designed to provide information on atmospheric temperature and humidity profiles [6] [7] [8]. MWHTS has an instantaneous field-of-view of 1.1 degrees and scans from nadir with 98 dif- 
ferent viewing angles at each side. The instrument measures thermal radiation at microwave frequencies ranging from $89-190.0 \mathrm{GHz}$. Atmospheric temperature profiles are primarily based on the measurements obtained at channels near $118.75 \mathrm{GHz}$, which is an oxygen absorption band. In particular, the MWHTS sounding channels $(2-9)$ respond to the thermal radiation at various altitudes as shown by their weighting function distributions. Channels 1 and 10 as window channels mainly detect radiation background, clouds, rain as well as surface properties. Since the satellite provides a nominal spatial resolution of $15 \mathrm{~km}$ at its nadir, the temperature perturbations from synoptic to mesoscale can be reasonably depicted. The instrument also contains five channels (11 - 15; see Table 1) and provides the atmospheric profile of moisture, as shown in Table 1.

Microwave humidity and temperature sounder (MWHTS) are onboard the Chinese FY-3C satellite with the purpose of retrieving atmospheric temperature and humidity profiles, rainfall and typhoon monitor [9] [10] [11], which is a cross-track scanning radiometer with a swath width of $2650 \mathrm{~km}$. MWHTS has a nadir footprint size of $15 \mathrm{~km}$, and 98 fields of view per scan line. The absolute visiting period is 5.5 days. The limitation threshold of matching domain is 0.05 degree for both altitude and longitude with 20 mins.

The fifteen channels from MWHTS are designed for sounding atmospheric

Table 1. Channel characteristics of MWHTS receivers.

\begin{tabular}{ccccccccc}
\hline $\begin{array}{c}\text { No. } \\
\text { frequency } \\
(\mathrm{GHz})\end{array}$ & Polarization & $\begin{array}{c}\text { Bandwidth } \\
(\mathrm{MHz})\end{array}$ & $\begin{array}{c}\mathrm{LO} \\
\text { precision } \\
(\mathrm{MHz})\end{array}$ & $\begin{array}{c}\text { Dynamic } \\
\text { range (K) }\end{array}$ & $\begin{array}{c}\mathrm{NE} \Delta \mathrm{T} \\
(\mathrm{K})\end{array}$ & $\begin{array}{c}\text { Calibration } \\
\text { accuracy } \\
(\mathrm{K})\end{array}$ & $\begin{array}{c}3 \mathrm{~dB} \\
\text { beam } \\
\text { width }\end{array}$ \\
\hline 1 & 89.0 & $\mathrm{~V}$ & 1500 & 50 & $3-340$ & 1.0 & 1.3 & $2.0^{\circ}$ \\
2 & $118.75 \pm 0.08$ & $\mathrm{H}$ & 20 & 30 & $3-340$ & 3.6 & 2.0 & $2.0^{\circ}$ \\
3 & $118.75 \pm 0.2$ & $\mathrm{H}$ & 100 & 30 & $3-340$ & 2.0 & 2.0 & $2.0^{\circ}$ \\
4 & $118.75 \pm 0.3$ & $\mathrm{H}$ & 165 & 30 & $3-340$ & 1.6 & 2.0 & $2.0^{\circ}$ \\
5 & $118.75 \pm 0.8$ & $\mathrm{H}$ & 200 & 30 & $3-340$ & 1.6 & 2.0 & $2.0^{\circ}$ \\
6 & $118.75 \pm 1.1$ & $\mathrm{H}$ & 200 & 30 & $3-340$ & 1.6 & 2.0 & $2.0^{\circ}$ \\
7 & $118.75 \pm 2.5$ & $\mathrm{H}$ & 200 & 30 & $3-340$ & 1.6 & 2.0 & $2.0^{\circ}$ \\
8 & $118.75 \pm 3.0$ & $\mathrm{H}$ & 1000 & 30 & $3-340$ & 1.0 & 2.0 & $2.0^{\circ}$ \\
9 & $118.75 \pm 5.0$ & $\mathrm{H}$ & 2000 & 30 & $3-340$ & 1.0 & 2.0 & $2.0^{\circ}$ \\
10 & 150.0 & $\mathrm{~V}$ & 1500 & 50 & $3-340$ & 1.0 & 1.3 & $1.1^{\circ}$ \\
11 & $183.31 \pm 1$ & $\mathrm{H}$ & 500 & 30 & $3-340$ & 1.0 & 1.3 & $1.1^{\circ}$ \\
12 & $183.31 \pm 1.8$ & $\mathrm{H}$ & 700 & 30 & $3-340$ & 1.0 & 1.3 & $1.1^{\circ}$ \\
13 & $183.31 \pm 3$ & $\mathrm{H}$ & 1000 & 30 & $3-340$ & 1.0 & 1.3 & $1.1^{\circ}$ \\
14 & $183.31 \pm 4.5$ & $\mathrm{H}$ & 2000 & 30 & $3-340$ & 1.0 & 1.3 & $1.1^{\circ}$ \\
15 & $183.31 \pm 7$ & $\mathrm{H}$ & 2000 & 30 & $3-340$ & 1.0 & 1.3 & $1.1^{\circ}$ \\
\hline
\end{tabular}

Note: In column 3, V/H means quasi $\mathrm{V} / \mathrm{H}$ polarization. 
temperature and water vapor in all weather conditions except for heavy precipitation [12]. Since these instruments are designed as cross-track scanners, the instrument viewing angle is different for different pixels along a scan line.

The horizontal resolution of MWHTS is $15 \mathrm{~km}$ at nadir. A combination of several imaging channels at frequencies of 89 , and $150 \mathrm{GHz}$ has been utilized to determine cloud liquid and ice water contents, because they directly respond to the emission from liquid droplets and the scattering from ice particles. MWHTS channels are non-polarized at nadir and mix-polarized off nadir. The polarization mixture reduces the angular dependence of the surface emissivity.

\section{Data Processing}

The Atmospheric Radiative Transfer Simulator (ARTS) developed for Satellite Data Assimilation and rapid calculations of satellite radiances. The atmospheric and surface conditions are used for producing global simulations of brightness temperatures that are measured by MWHTS. The vertical profiles of temperature, specific humidity, and pressure, the surface parameters of surface skin temperature, 2-m wind speed, and wind direction from the National Center for Environmental Prediction (NCEP) 6-h reanalysis data are used as input to WRF, along with sensor's (MWHTS) zenith angle and scan angle serving as additional input to ARTS [13] [14]. The NCEP/WRF data field shave a horizontal resolution $0.05^{\circ} \times 0.05^{\circ}$ and 29 vertical levels, with the highest vertical level located near $0.1 \mathrm{hPa}$.

In ARTS, the atmosphere is gridded by latitude, longitude, and pressure coordinates. Because radiative transfer calculations with scattering are generally much more expensive than clear sky radiative transfer, scattering calculations are confined to a sub-domain of the modeled atmosphere called the cloud box. In this study, we consider spherical and cylindrical ice particles, with either completely random orientation or horizontally alignment with random azimuthally orientation. The single-scattering properties for these particles are obtained software derived from the random and fixed matrix codes of Mishchenko. Because of the computational expense of the matrix calculations, single-scattering properties are pre-calculated, imported in XML format, and interpolated as required. The complex refractive index of ice is obtained from the tabulated data of Warren.

Considering the calibration accuracy and model error, bias correction of brightness temperature is in need. The calibration accuracy consists of contributions distributed in four parts: uncertainty of cold target, warm target, nonlinear term and the random noise of receiver. Table 2 shows the expression of calibration accuracy [15].

\section{Case Study}

The statistical retrieval method and the physical retrieval method are used to retrieve the atmospheric temperature profiles in our study. The $\mathrm{NN}$ algorithm and 
Table 2. Primary calibration results of MWHTS.

\begin{tabular}{ccccccc}
\hline Channel & $\Delta \mathrm{T}_{\mathrm{W}}(\mathrm{K})$ & $\Delta \mathrm{T}_{\mathrm{C}}(\mathrm{K})$ & $\Delta \mathrm{T}_{\mathrm{NL}}(\mathrm{K})$ & $\Delta \mathrm{T}_{\mathrm{SYS}}(\mathrm{K})$ & $\Delta \mathrm{T}_{\mathrm{CAL}}(\mathrm{K})$ & $\begin{array}{c}\Delta \mathrm{T}_{\text {CAL }}(\mathrm{K}) \\
\text { Without } \Delta \mathrm{T}_{\text {SYS }}\end{array}$ \\
\hline $89 \mathrm{GHz}$ & 0.1 & 0.1 & 0.33 & 0.32 & 0.48 & 0.36 \\
$118 \mathrm{GHz}-1$ & 0.2 & 0.1 & 0.50 & 2.64 & 2.70 & 0.55 \\
$118 \mathrm{GHz}-2$ & 0.2 & 0.1 & 0.14 & 0.99 & 1.02 & 0.26 \\
$118 \mathrm{GHz}-3$ & 0.2 & 0.1 & 0.23 & 0.85 & 0.91 & 0.32 \\
$118 \mathrm{GHz}-4$ & 0.2 & 0.1 & 0.20 & 0.81 & 0.86 & 0.30 \\
$118 \mathrm{GHz}-5$ & 0.2 & 0.1 & 0.17 & 0.75 & 0.80 & 0.28 \\
$118 \mathrm{GHz}-6$ & 0.2 & 0.1 & 0.19 & 0.74 & 0.80 & 0.29 \\
$118 \mathrm{GHz}-7$ & 0.2 & 0.1 & 0.23 & 0.38 & 0.50 & 0.32 \\
$118 \mathrm{GHz}-8$ & 0.2 & 0.1 & 0.16 & 0.40 & 0.49 & 0.28 \\
$150 \mathrm{GHz}$ & 0.1 & 0.1 & 0.24 & 0.40 & 0.49 & 0.28 \\
$183 \mathrm{GHz}-1$ & 0.2 & 0.1 & 0.25 & 0.57 & 0.66 & 0.34 \\
$183 \mathrm{GHz}-2$ & 0.2 & 0.1 & 0.14 & 0.45 & 0.27 & 0.26 \\
$183 \mathrm{GHz}-3$ & 0.2 & 0.1 & 0.27 & 0.36 & 0.50 & 0.35 \\
$183 \mathrm{GHz}-4$ & 0.2 & 0.1 & 0.59 & 0.37 & 0.73 & 0.63 \\
$183 \mathrm{GHz}-5$ & 0.2 & 0.1 & 0.28 & 0.35 & 0.50 & 0.36 \\
\hline & & & & & & \\
\hline
\end{tabular}

the $1 \mathrm{D}$-var algorithm are generally taken as the statistical method and the physical method, respectively, which both can represent the nonlinear relationship between the satellite observation and the atmospheric temperature.

\subsection{Neural Networks Retrieval Algorithm (NN)}

The study area is the North Atlantic Ocean, located between $20^{\circ}-40^{\circ} \mathrm{N}$ and $60^{\circ}$ - $80^{\circ} \mathrm{W}$, as shown in Figure 1.

An Atlantic hurricane or tropical storm is a tropical cyclone that forms in the Atlantic Ocean, usually in the summer or fall. A hurricane occurs in the Atlantic Ocean and northeastern Pacific Ocean, while a typhoon occurs in the northwestern Pacific Ocean, and a cyclone occurs in the south Pacific or Indian Ocean.

Matthew happened from Sept 28 to Oct 10, 2016. Typhoons cause serious economic damage and casualties; it is the one important severe weather system which influences our country. Therefore, the path of typhoon forecast has caught people's more attention. There are much research and establish various forecasting methods including numerical model of dynamic prediction and objective statistical forecast, subjective experience forecast.

Currently, several techniques exist to extract humidity from the satellite observations. First, a retrieval technique can be used to derive humidity from satellite observations in the same form as conventional observations [16]. These retrievals are then assimilated in the same way as conventional observations to produce analyses. Second, radiances are directly assimilated into a variational analysis system. Essentially, humidity profiles are iterated until a best agreement 


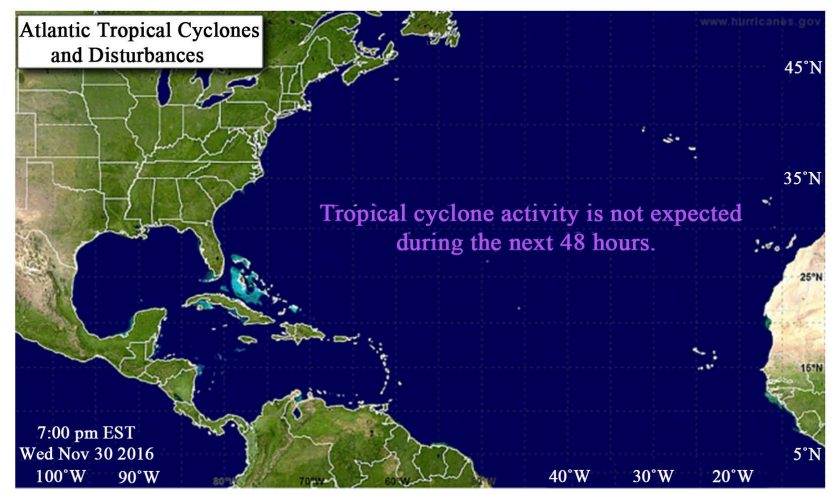

Figure 1. Domain chosen in this case.

in the least squares sense is found between the observed and simulated radiances. Short-term forecasts are used as a first guess. The resulting humidity profiles then form the analyses. Third, a hybrid technique is used between the two aforementioned techniques.

\subsection{Experiments and Analysis}

Figure 2 shows the brightness temperatures observed using channel 10 from MWHTS onboard FY-3C, with starting time of 12:55, Oct 8, 2016 and 13:14, Oct 7, 2016.

Simulations datasets using radiative transfer model are calculated as Figure 3, where the input data are from WRF model with NCEP FNL data. In this study, the inversion of observations including the corrected brightness temperatures of MWHTS in the testing dataset, into atmospheric temperature and humidity profiles was carried out by the ANN algorithm and the 1D-var algorithm. Bias and RMSE are taken as the standard quantification to validate the retrieval results with WRF outputs and ECMWF reanalysis, which are used as the truth. According to the Weighting Functions analysis of the MWHTS, we validate the temperature and humidity retrievals at 32 pressure levels from $10-1000 \mathrm{hPa}$ as Figure 4 shows.

The corrected brightness temperatures of the MWHTS are taken individually as the inputs of the $\mathrm{NN}$ retrieval algorithm, and the outputs are the temperature and humidity retrievals. The retrieval validation results are shown in Figure 5.

According to the comparison of the retrieval results in typhoon area, we can find that the MWHTS has the better detection ability of temperature and humidity at levels from surface to $900 \mathrm{hPa}$ due to the weighting function distribution of multi-channel observation. This can offer a possibility for improving the MWHTS retrieval accuracy of temperature and humidity profiles in the atmospheric layers using the MWHTS observations.

\section{Conclusion and Future Work}

The results provided by this study will provide more confidence to satellite-based atmospheric profiles applications in hurricane domains. A previous 


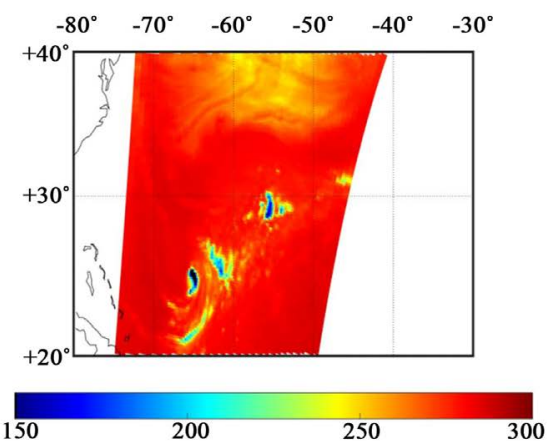

(a)

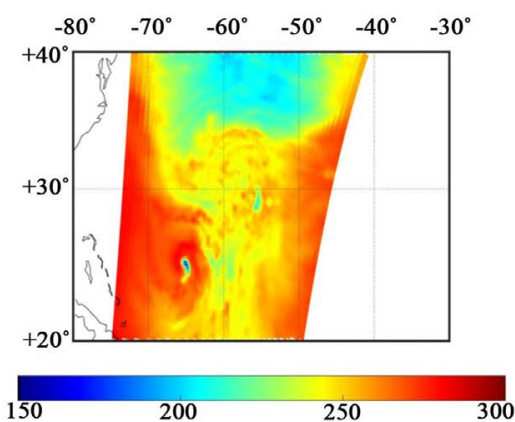

(c)

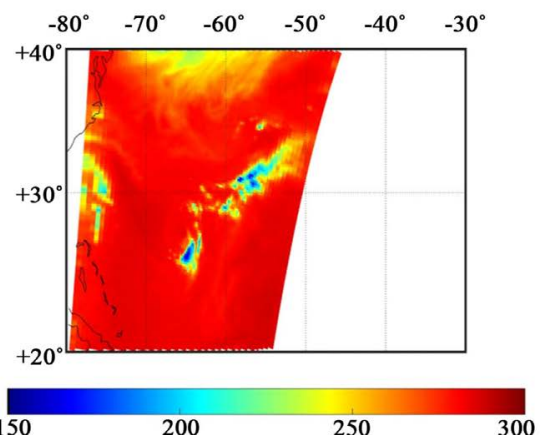

(b)

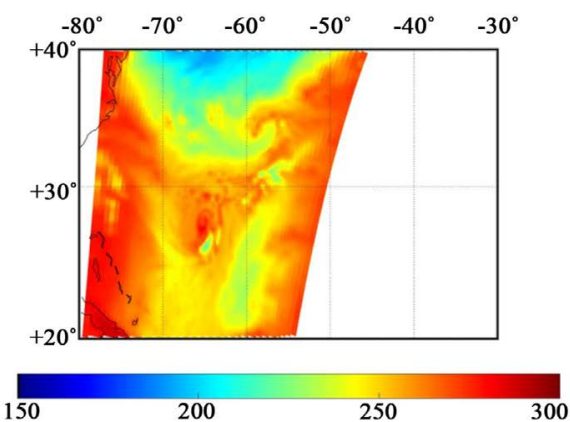

(d)

Figure 2. Observations from MWHTS on board FY-3C satellite. (a) Channel 1, 12:55, Oct 8, 2016; (b) Channel 1, 13:14, Oct 7, 2016; (c) Channel 10, 12:55, Oct 8, 2016; (d) Channel 10, 13:14, Oct 7, 2016.
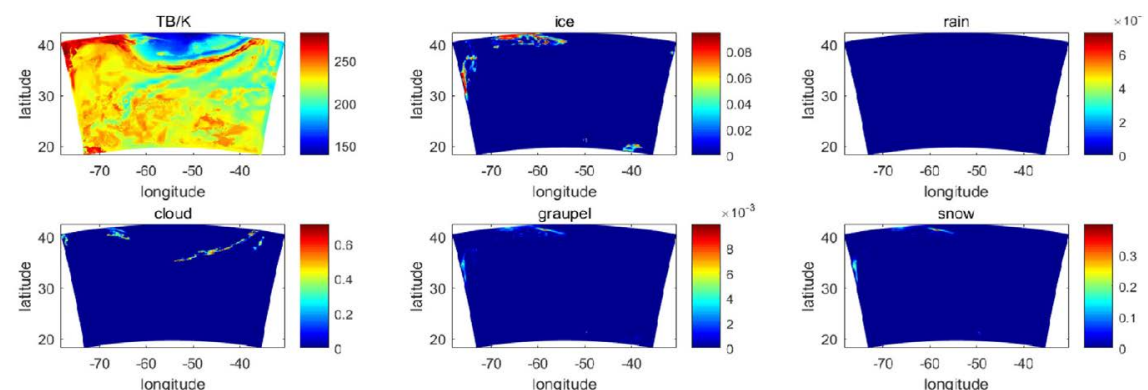

longitude
vapor
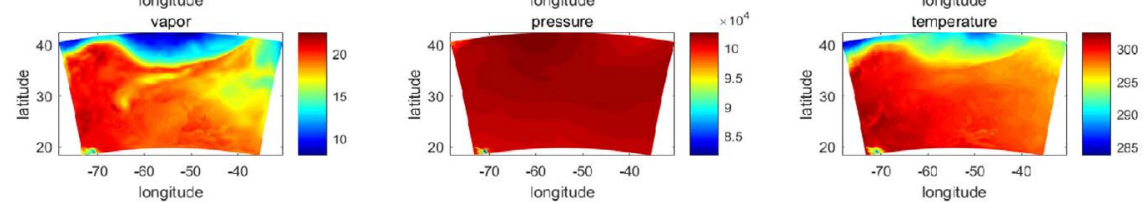

Figure 3. Atmospheric parameters and simulating brightness temperatures.

study has shown satellite-based precipitation is a better choice in the North Atlantic Ocean where rain gauge observation is sparse and unevenly distributed. The improvements of this paper will further advance meteorological studies in this region.

In order to evaluate the detection ability of atmospheric temperature of 118.75 $\mathrm{GHz}$ oxygen absorption line, we focus on the observed brightness temperatures of the MWHTS. The radiometric information contents of MWHTS temperature sounding channels are calculated; the atmospheric temperature and water vapor 

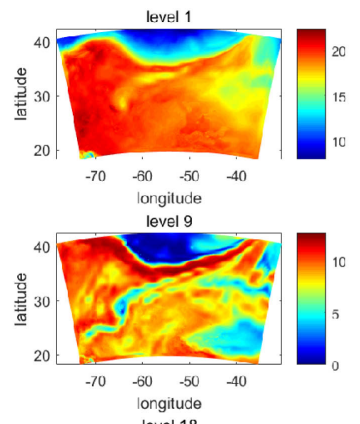$$
\text { (evel } 18
$$

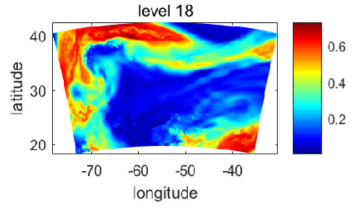

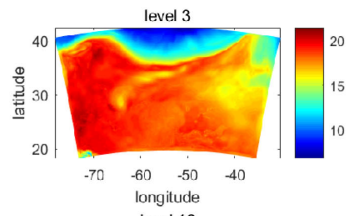

level 12

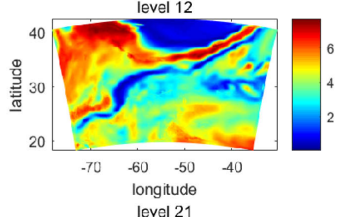

longitude

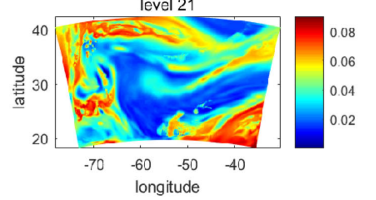

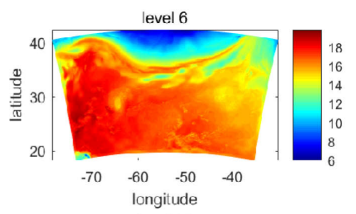

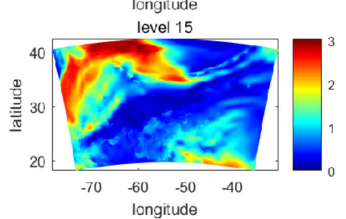

longitude
level 24

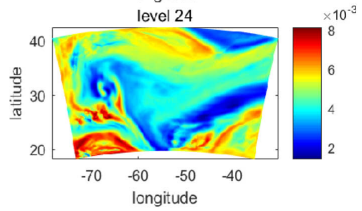

Figure 4. Water vapor density distribution in different atmospheric layers.

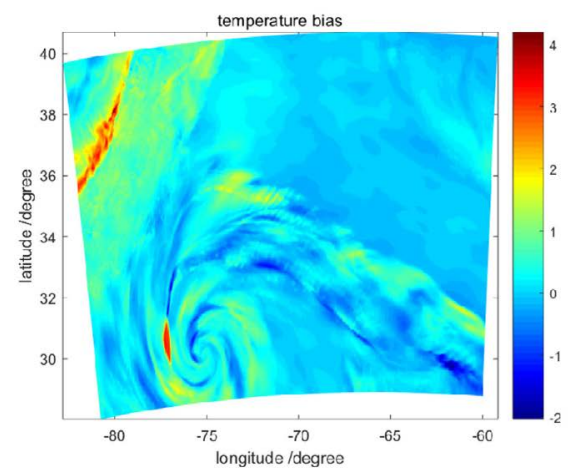

(a)

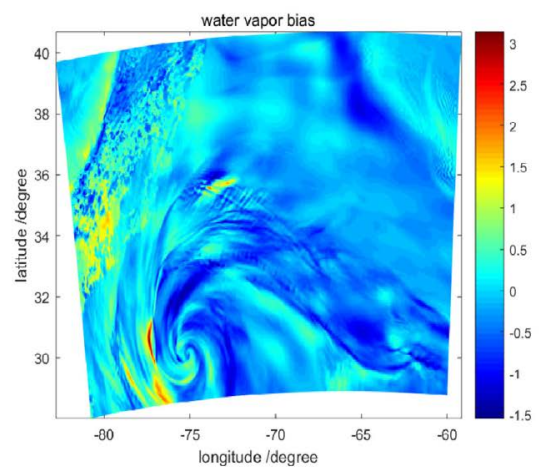

(b)

Figure 5. Retrievals using the NN algorithm and 1DVar algorithm. (a) Map of Temperature bias; (b) Map of water vapor bias.

profiles are retrieved using the $\mathrm{NN}$ algorithm and the $1 \mathrm{D}$-var algorithm from MWHTS. In our study, the MWHTS observed brightness temperatures, which represent $118.75 \mathrm{GHz}$ and $183.31 \mathrm{GHz}$ observations respectively, are used to carry out the retrieval trails of the atmospheric temperature and water vapor profiles.

These are substantially smaller than the a priori temperature profile variations, demonstrating that $118-\mathrm{GHz}$ aircraft or satellite observations can provide useful information on atmospheric vertical thermal structure. Combined with $183 \mathrm{GHz}$ and window channels, water vapor profiles are also retrieved accurately to be used in Matthew typhoon and climate analysis and data assimilation model which validates the positive impacts in extreme weather forecasting and analysis in hurricane study case.

\section{Acknowledgements}

This work was supported by the Young Elite Scientist Sponsorship Program by Central Military Commission Equipment Pre-research Fund Project (6140136010116ZK24001). 


\section{Conflicts of Interest}

The authors declare no conflicts of interest regarding the publication of this paper.

\section{References}

[1] Petty, G.W. (1994) Physical Retrievals of Over-Ocean Rain Rate from Multichannel Microwave Imagery. Part I: Theoretical Characteristics of Normalized Polarization and Scattering Indices. Meteorology \& Atmospheric Physics, 54, 79-99. https://doi.org/10.1007/BF01030053

[2] Draper, D.W., Newell, D.A., Wentz, F.J. and Skofronick-Jackson, G.M. (2015) The Global Precipitation Measurement (GPM) Microwave Imager (GMI): Instrument Overview and Early On-Orbit Performance. IEEE Journal of Selected Topics in Applied Earth Observations \& Remote Sensing, 8, 3452-3462.

https://doi.org/10.1109/JSTARS.2015.2403303

[3] Blackwell, W.J. and Chen, F.W. (2009) Neural Networks in Atmospheric Remote Sensing. Artech House, Norwood, MA.

[4] Tikhonov, A.N., Goncharsky, A.V., Stepanov, V.V. and Yagola, A.G. (2013) Numerical Methods for the Solution of Ill-Posed Problems. Springer Science and Business Media, Dordrecht, Netherlands.

[5] Engeln, A.V., Nedoluha, G., Kirchengast, G. and Bühler, S. (2003) One-Dimensional Variational (1-D Var) Retrieval of Temperature, Water Vapor, and a Reference Pressure from Radio Occultation Measurements: A Sensitivity Analysis. Journal of Geophysical Research Atmospheres, 108, 4337.

https://doi.org/10.1029/2002JD002908

[6] He, J., Zhang, S. and Wang, Z. (2015) Advanced Microwave Atmospheric Sounder (AMAS) Channel Specifications and T/V Calibration Results on FY-3C Satellite. IEEE Transactions on Geoscience \& Remote Sensing, 53, 481-493. https://doi.org/10.1109/TGRS.2014.2324173

[7] Zhang, S.W., Li, J. and Wang. Z.Z. (2012) Design of the Second Generation Microwave Humidity Sounder (MWHS-II) for Chinese Meteorological Satellite FY-3. 2012 IEEE International Geosciences and Remote Sensing Symposium (IGARSS 2012), Munich, Germany, 22-27 July 2012, 4672-4675.

[8] He, J. and Zhang, S. (2015) Research on Global Profiles and Precipitation Retrievals for FY-3C MWHTS. 2015 IEEE International Geosciences and Remote Sensing Symposium (IGARSS 2015), Milan, Italy, 26-31 July 2015, 4890-4893.

[9] He, J.Y., Zhang, S.W. and WANG, Z.Z. (2012) The Retrievals and Analysis of Water Vapor Density in Arctic Regions Using FY-3A Satellite MWHS. Radio Science, 47, 301-311.

[10] He, J.Y. and Zhang, S.W. (2012) Humidity Retrievals in Mid-Latitude and Tropical Regions Using FY-3 MWHS. Journal of Remote Sensing, 3, 581-597.

[11] Yang, Z.D., Lu, N.M. and Shi, J. (2013) Overview of FY-3 Payload and Ground Application System. IEEE Transactions on Geoscience and Remote Sensing, 12, 4846-4853.

[12] Surussavadee, C. and Staelin, D.H. (2008) Global Millimeter-Wave Precipitation Retrievals Trained with a Cloud-Resolving Numerical Weather Prediction Model, Part I: Retrieval Design. IEEE Transactions on Geoscience and Remote Sensing, 46, 99-108. https://doi.org/10.1109/TGRS.2007.908302

[13] Rodgers, C.D. (2000) Inverse Methods for Atmospheric Sounding. World Scientific 
Publishing, New York. https://doi.org/10.1142/3171

[14] Surussavadee, C. and Staelin, D.H. (2008) Global Millimeter-Wave Precipitation Retrievals Trained with a Cloud-Resolving Numerical Weather-Prediction Model, Part II: Performance Evaluation. IEEE Transactions on Geoscience and Remote Sensing, 46, 109-118. https://doi.org/10.1109/TGRS.2007.908299

[15] He, J., Wang, Z. and Zhang, S. (2016) T/V Calibration for Microwave Humidity and Temperature Sounder onboard Chinese FY-3D Satellite. 2016 Progress in Electromagnetic Research Symposium (PIERS), Shanghai, 8-11 August 2016, 510-514.

[16] Blackwell, W.J. (2005) A Neural-Network Technique for the Retrieval of Atmospheric Temperature and Moisture Profiles from High Spectral Resolution Sounding Data. IEEE Transactions on Geoscience and Remote Sensing, 43, 2535-2546.

https://doi.org/10.1109/TGRS.2005.855071 